\title{
Welfare Regime Variation in the Impact of the Great Recession on Deprivation Levels: A Dynamic Perspective on Polarisation vs Convergence for Social Risk Groups, 2005-2014
}

\section{DOROTHY WATSON*, RAFFAELE GROTTI*****iD, CHRISTOPHER T. WHELAN*** AND BERTRAND MAITTRE*****}

\author{
*The Economic and Social Research Institute, Dublin \\ email: dorothy.watson@esri.ie \\ ** Department of Political and Social Sciences, European University Institute, Florence \\ ${ }^{* * *}$ Department of Sociology and Social Research, University of Trento, Trento \\ email: raffaele.grotti@unitn.it \\ ***** School of Sociology, UCD Geary Institute, University College Dublin, Dublin \\ email: christopher.whelan@ucd.ie \\ ****** The Economic and Social Research Institute, Dublin \\ email: bertrand.maitre@esri.ie
}

\begin{abstract}
This paper investigates changes over the period 2005 to 2014 in material deprivation dynamics of social risk groups in 11 European countries covering a range of welfare regimes. The period covered experienced dramatic economic change, encompassing periods of boom, the Great Recession and early recovery. Social risk groups are defined as groups which differ in the challenges that they face in converting resources into desired outcomes. The comparative element of the paper allows us to assess whether certain welfare regimes were better at protecting more vulnerable groups. Results, based on the longitudinal component of the European Union Statistics on Income and Living Conditions and on analysis of deprivation dynamics between pairs of years, showed large inequality between groups in the risk of persistent deprivation - with lone parents and people with disability most at risk in all countries. Variation across welfare regimes was restricted to the contrast between the liberal and the remaining regimes. Countries belonging to the former regime (UK and Ireland) were distinctive in showing the largest social risk gap in persistent deprivation and were the only ones which experienced substantial polarisation between groups with the Great Recession.
\end{abstract}

Keywords: Poverty; Deprivation dynamics; Social risk groups; Great Recession; Comparative welfare regimes; European Union Statistics on Income and Living Conditions

\section{Introduction}

The Great Recession of 2007-2008, which followed on the bursting of the US housing bubble and the global financial crisis, caused dramatic changes in the economic 
circumstances of families. This has prompted vigorous debate on whether the recession led to a polarisation in deprivation and living standards or a 'squeezed middle' where the middle classes were worse affected (Whelan et al., 2017). In this paper, we extend this discussion by adopting a comparative perspective on the social stratification of changing patterns of deprivation dynamics.

Extending earlier discussions relating to social class, we focus on 'social risk' groups. These groups are likely to differ in their risk of negative outcomes due to non-social class, personal or family factors, including life-course stages. The comparative element of the paper recognizes that European countries were unevenly hit by the recession and that the negative consequences of the recession were cushioned/exacerbated by different national welfare regime arrangements.

Our analysis focuses on deprivation dynamics of 'social risk' groups across eleven European countries representing a range of welfare regimes between 2005 and 2014. Our descriptive analyses draw on the longitudinal component of the European Union Statistics on Income and Living Conditions (EU-SILC) data and our dynamic perspective builds on the analysis of adjacent years for three critical periods.

Our paper focuses on three key research questions:

- Is the pattern of 'social risk' group differentiation in persistent deprivation similar across countries and welfare regimes?

- Is the 'social risk gap' - the absolute difference in deprivation across groups larger in less generous welfare systems?

- Did the recession lead to polarisation between the vulnerable social risk groups and the more advantaged groups?

\section{The concept of social risk groups}

The conceptual understanding of social risk was developed in contrast to social class as an important principle of differentiation. Following the Weberian tradition, social classes can be distinguished based on differing command over market resources (Goldthorpe, 2007). As Goldthorpe (2007b: 13) observes, one of the primary objectives of the development of social class schemas is to bring out the constraints and opportunities typical of different class positions as they bear on 'individuals' security, stability and prospects'. As Goldthorpe and Jackson (2008: 528) stress, where economists' notion of 'permanent income' can be measured only in a 'one-shot' fashion, social class may provide important information relating to longer-term command over resources.

Nevertheless, social class distinctions do not capture all the principles of differentiation that are relevant to a heightened risk. Life-course differences are an important element in distinguishing between groups, because of norms regarding the distribution of work across life stages and regarding the 
distribution of caring roles (Macmillan and Copher, 2005). The development of the European welfare state has been linked to a political commitment to smoothing out the supply of resources across the life course (Dewilde, 2003; Leisering and Liebfried, 1999). However, the life course perspective does not adequately encompass certain other dimensions of inequality to which the welfare state responds, such as lone parenthood, illness and disability, and barriers to labour market entry (Freeman and Rothgang, 2010; Gibson-Davis, 2016; Priestley, 2010; Kenworthy, 2010). Life-course differences can be considered as a subset of a broader range of non-market social risks whose consequences are addressed by the welfare state. Social risk, in this sense, could be seen as associated with challenges arising from the increasing 'commodification' of welfare in the postindustrial economy, whereby needs are increasingly met through the market rather than through the family or as an entitlement from the state (TaylorGooby, 2004; Esping-Andersen, 1990).

If social class captures differences in market power, 'social risk' captures barriers to accessing the market in the first place and the ability to convert such access into economic resources. Our focus on social risk can be located within the ongoing debate on the salience of social class in structuring social exclusion. Pintelon et al. (2013) note that the continued relevance of social class has been challenged by two partly competing perspectives. The individualization thesis (Beck, 1992) draws attention to a range of factors including diversification of family structures which contribute to a diversification of routes into poverty resulting in a more heterogeneous poor population. The life-course perspective also challenges the traditional class perspective in focusing on social risks associated with a phase in the person's life trajectory (Vandecasteele, 2010). TaylorGooby (2004) connects new social risks with the life-course as the former are frequently associated with earlier stages of the life-cycle including entry to the labour force and care responsibilities at the stage of family formation. However, the perspective can incorporate a range of risks which are not adequately captured by hierarchical stratification structures such a social class.

Social risks are associated with both access to resources generated in the labour market and the ability to convert such resources into desirable outcomes. Looking at such risks implies a focus shift towards non-traditional social stratification factors as well as further consideration of the outcomes which we direct our attention to. Sen's (2009) capability approach argues that in understanding poverty, people's resources are only of instrumental importance in signalling what they enable a person to be or do; while what is of intrinsic importance is what a person can be or do. As Hick and Burchardt (2016:75) observe, this distinction is important as individuals differ in the resources required to achieve a specific level of functioning. Sen (1992: 26-38) labels these variations 'conversion factors'. Thus, the ability to convert resources into the typical bundle of goods and services considered normative in a society may be qualified by a range 
of additional factors relating to needs and associated demands and restrictions (Alkire et al., 2015; Ringen, 1988).

The primary concepts of the capability approach are functionings and capabilities. A 'functioning' is something a person succeeds in doing or being (Sen, 2009: 75) while a person's 'capability' refers to the 'alternative combinations of functionings a person can achieve, and from which he or she can choose one collection' (Sen, 1992: 31). Thus, for Sen the relationship between resources is variable and deeply contingent. This has relevance for poverty analysis given the continued dominance of income-centric approaches to understanding poverty (Hick and Burchardt, 2016: 77). While capabilities have priority over functionings in Sen's framework, operational difficulties in capturing the former have led to arguments for focusing on the latter. Sen (1992: 112) has suggested that it may be possible to use information about a person's functionings to draw inferences about their relatively basic capabilities - where we are confident that differences in outcomes are not a matter of choice. This is important for our later discussion of the relative advantages of income and deprivation indicators.

In what follows we discuss the impact of a range of factors that have implication for one's ability to participate in the labour market and to convert resources into a variety of desirable outcomes relating to both current and persistent income poverty and deprivation. Here we distinguish non-market differentiation challenges to meeting one's material needs that are linked to:

- Life-course stage: children and people older than 'working-age';

- Personal resources: illness or disability may limit a person's capacity to work as well as involve additional costs associated with treatment, medication or disability-specific devices and aids;

- Non-work caring responsibilities: responsibility for childcare or others who have an illness or disability is likely to reduce the time available for paid work;

- Barriers to labour market entry that affect young adults who are seeking their first jobs.

\section{Comparative welfare regime perspective}

Individuals in Western economies meet their needs through markets, families and the state (Esping-Andersen, 1990). Markets are the main source of welfare for most working-age adults because their incomes come via labour and many of their welfare needs are met through purchasing goods and services. Families provide welfare through care services (mainly for children and adults with a disability), through pooling of incomes from the market and pooling of risks including the income shocks associated with illness or unemployment (Daly, 2002; Western et al., 2012). Finally, states provide welfare by virtue of a redistributive social contract which has its roots in collective solidarity. ${ }^{1}$ 
In identifying the regimes set out below, we combine the classic EspingAndersen (1990) threefold schema, subsequently extended with a fourth (Southern) regime by Ferrera (1996), with employment regime typologies (Gallie and Paugam, 2000). Gallie and Paugam (2000) focus on the degree of benefit coverage and level of financial compensation for the unemployed and the scale of active employment policies. Focusing on European countries which are similar in terms of level of economic development, we distinguish the following regimes: ${ }^{2}$

The social-democratic regime is characterised by its emphasis on universalism and redistribution. Employment flexibility is combined with generous social welfare and unemployment benefits to guarantee adequate economic resources independently of market or family. From this regime, we focus on Sweden, Finland and the Netherlands.

The corporatist regime places less emphasis on redistribution. Rights to benefits depend on being already inserted in the labour market with entitlements linked to lifelong employment. There is a greater emphasis on income protection and transfers and less emphasis on the provision of services. We include Austria, Belgium and France from this regime type.

The liberal regime emphasises provision through the market with the state acting only to support the market. Social benefits are typically targeted, using means tests, though there has been a recent shift towards negative income tax policies. These countries are characterised by flexible labour markets and low provision of services to promote and sustain employment. We include Ireland and the UK as representatives of this regime.

The southern regime is characterised by an emphasis on family as the provider of welfare with labour market policies relatively undeveloped and selective. The benefit system tends to be uneven and minimalist with no guaranteed minimum income. From this regime, we include Italy, Spain and Greece.

Transfers through the family across the life-course take place in all regimes but the form of the transfers can vary. In the social-democratic countries, financial transfers from older parents to adult children are more common than elsewhere. However, the amounts transferred tend to be the highest in Spain and Italy. The main form of support from older parents towards adult children in the southern regime is via prolonged co-residence (Attias-Donfut et al., 2005; Kohli and Albertini, 2008; Albertini et al., 2007).

\section{Conceptual and methodological aspects of income poverty and deprivation}

Here we argue that our ability to proxy capabilities with functionings - following Sen -, will strengthen by moving our focus from point-in-time measures of disadvantages to the persistence of disadvantages. In addition, we argue that such ability can be further enhanced by focusing on material deprivation rather than 
income. A large body of research has criticized the use of income alone (Ringen, 1988; Nolan and Whelan, 2011). Comparative European analysis has shown that the overlap between income poverty and deprivation measures is modest. The findings suggest that this is related to the extent to which current disposable income serves as an adequate proxy for longer-term resources. However, even when measured over time and adjusted for measurement error, income poverty and deprivation continue to capture distinct phenomenon, despite being substantially correlated (Kus et al., 2016).

In brief, using indicators of material deprivation instead of income allows to better identify the poor and to capture what being poor means. In fact, deprivation indicators directly capture the multifaceted nature of poverty and social exclusion. While the specific focus of the paper is on persistent material deprivation, in the following we discuss income poverty dynamics because much of the existing literature has focused on poverty and, importantly, most of the following discussion can arguably be applied to deprivation.

Research based on panel data has established that poverty is an experience of varying duration (Bane and Ellwood, 1986; Jenkins, 1999; Fouarge and Layte, 2005). The distinction between persistent and transient poverty is also important because the two have very different policy implications (Walker, 1994). Whether many people experience poverty but quickly escape from it or poverty is a persistent and long-term phenomenon strongly matters. Persistent poverty has more serious consequences for a range of outcomes such as current and future labour market outcome, family behaviours/decisions, health, well-being and child development (Duncan and Brooks-Gunn, 1999; Power et al., 1999). In this paper, we follow Polin and Raitano (2014), and Ayllón and Gábos (2017) who define persistence as being income poor or deprived in the current year and in the previous year.

\section{Existing research}

Several recent studies have focused on material deprivation (Guio et al., 2017; Ayllón and Gábos, 2017). Guio and Marlier (2017) employed EU-SILC data to analyse the evolution of material deprivation over time across the EU. They found that the increase in the level of material deprivation characterizing the countries most affected by the recession was the result of both an increase in entry rates into material deprivation and a decrease in exit rates. In an extension of this work Guio et al. (2017) examined which material deprivation items people do without as their income decrease. There is a high level of similarity across countries in the items that are curtailed. Across the six items available in the longitudinal EU-SILC data for 2011, the first item to be curtailed was an annual holiday, followed by the capacity to meet unexpected expenses, a protein meal, keeping the home adequately warm, avoiding arrears, and having a car or van. Based on the 13 items available in the cross-sectional EU-SILC data 
for 2009, the order of curtailment was the following: inability to afford holiday, unexpected expenses, replacing worn-out furniture, pocket money, leisure activity, drink/meal out with friends, new clothes, protein meal, keeping home warm, avoiding arrears, a car/van, computer/internet, new shoes.

Research on eight countries using EU-SILC data has found a high level of persistence of income poverty and a somewhat lower level of persistence of severe material deprivation between waves (Ayllón and Gábos, 2017) with a very strong persistence of low work intensity. ${ }^{3}$ All three indicators showed evidence of genuine state dependence between waves, namely being in the state in one wave was causally related to being in the state in a subsequent wave even when individuals' observed and unobserved characteristics were taken into account.

\section{Data and methods}

In this study, we draw on the longitudinal component of the EU-SILC data over the period 2005 to 2014 that allows us to examine the impact of the boom, recession and early recovery on trends in deprivation for the different social risk groups. ${ }^{4}$ More precisely, we focus on pairs of years in three periods and examine transitions between waves: pre-recession (2005-2006), early recession (20082009) and early recovery (2013-2014). The EU-SILC is an annual survey that collects information on households and individuals across a wide range of social and economic domains from individual income and household income to labour market status, health, education, housing. The survey was launched in 2003 and the data is output-harmonised to allow European comparisons. The EU-SILC is used to monitor poverty, social inclusion and living conditions across EU-member states within the Europe 2020 strategy. ${ }^{5}$

The EU-SILC longitudinal component follows a 4-years rotational design, where every year $25 \%$ of the sample exits the survey and a new random sample of household enters the survey. ${ }^{6}$ Although EU-SILC follows individuals for up to four waves, the number of cases available for analysis declines very rapidly as the period of observation extends because of the high rate of 'field' attrition - which is particularly high in countries such as the UK and Ireland (Grotti et al., 2017; Jenkins and Van Kerm, 2017). For this reason, we follow Krell, Frick and Grabka (2017) and focus on transitions between pairs of waves rather than following people across longer periods of time. This also minimizes the potential for nonrandom attrition to influence the results (Ayllón, 2008; Cappellari and Jenkins, 2004; Jenkins and Van Kerm, 2017). Given the limitation of the data available to us, our focus is inevitably on short-term effects. However, we recognise the need for further exploration of longer-term consequences (Brandt and Hank, 2013). This is likely to be particularly crucial in the case of children; hopefully such effects can ultimately be explored, making use of longitudinal cohort data. 
TABLE 1. Number of cases available by country and pair of years.

\begin{tabular}{|c|c|c|c|c|}
\hline & & $2005-06$ & 2008-09 & 2013-14 \\
\hline \multicolumn{5}{|c|}{ Social-democratic regime } \\
\hline SE & Sweden & 10,483 & 10,865 & 7,051 \\
\hline NL & Netherlands & 17,164 & 15,851 & 16,368 \\
\hline FI & Finland & 12,697 & 10,971 & 18,577 \\
\hline \multicolumn{5}{|c|}{ Corporatist regime } \\
\hline $\mathrm{AT}$ & Austria & 9,183 & 8,690 & 8,381 \\
\hline $\mathrm{BE}$ & Belgium & 8,049 & 9,122 & 9,389 \\
\hline FR & France & 15,152 & 19,578 & 19,742 \\
\hline \multicolumn{5}{|c|}{ Liberal regime } \\
\hline UK & United Kingdom & 15,018 & 11,761 & 14,989 \\
\hline IE & Ireland & 5,708 & 6,242 & 5,660 \\
\hline \multicolumn{5}{|c|}{ Southern regime } \\
\hline ES & Spain & 22,654 & 24,605 & 20,558 \\
\hline IT & Italy & 36,939 & 34,676 & 29,704 \\
\hline EL & Greece & 9,954 & 11,798 & 12,866 \\
\hline
\end{tabular}

Source: EU-SILC data.

We focus on eleven countries selected to reflect welfare regimes variation see Table 1 (Esping-Andersen, 1990; Eurofound, 2007; Watson et al., 2014). Our sample includes all individuals of any age who are observed for two consecutive waves, namely in both 2005 and 2006; or 2008 and 2009; or 2013 and 2014. The final samples size are shown in Table 1.

All the results in the paper are based on descriptive analyses and we use statistical modelling to test for the significance of the differences in material deprivation between social risk groups. All the analyses adjust the standard errors for weighting of the data and clustering of the observations at household level. We employ longitudinal weights to ensure that the longitudinal sample is representative of the national population.

\section{Measuring deprivation}

We use the official measure of material deprivation as endorsed in 2009 by the EU (European Commission, 2015). Material deprivation is measured at the household level with the score attributed to all household members. It involves living in a household that is unable to afford 3 or more out of the following 9 basic goods and services:

1. To pay on time mortgage, rent, utility bills, hire purchase or other loan payments;

2. One week's annual holiday away from home;

3. A meal with meat, chicken, fish (or vegetarian equivalent) every second day; 
4. To meet unexpected financial expenses (set amount corresponding to the monthly national at-risk-of-poverty threshold of the previous year);

5. A telephone (including mobile phone);

6. A colour TV;

7. A washing machine;

8. A car;

9. To keep its home adequately warm.

The content of the items and the focus on affordability together with our subsequent focus on persistent deprivation is consistent with our desire to capture genuinely enforced deprivation and thus to provide, in Sen's terms, as solid a basis as possible for inferences from functionings to capabilities.

Although a newer indicator of deprivation is being introduced, which includes a wider range of items (see Guio and Marlier, 2017), we focus on the nine-item indicator here since it is available for the three periods we examine. Although examining the nine material deprivation indicators one at a time might provide some additional insights, we are reluctant to do this because the material deprivation index has been constructed and tested for validity and reliability as a composite measure. An examination of the number of items lacked has shown that the recession not only has pushed more households into material deprivation, but has also intensified its impact (Guio et al., 2017).

\section{Results}

\section{The context}

The period from 2005 to 2014 is one of dramatic economic change, encompassing a period of economic growth, the Great Recession, and early recovery. Accordingly, in this paper we focus on three pairs of years: 2005-2006, a period where unemployment rates were generally stable or falling; 2008-09, the period with the sharpest rise in unemployment in most of the countries; and 2013-14, the early recovery period in the countries characterized by the biggest rise in unemployment with the recession.

Figure 1 shows the unemployment rate and the deprivation rate from 2005 to 2014 across the eleven countries we examine in this study. In this figure, as well as in those which follow, countries are ordered according to the welfare regimes they belong to: from the left to right (here also from the top to the bottom) we have the social-democratic regime ( $\mathrm{SE}, \mathrm{NL}$ and $\mathrm{FI})$; the corporatist regime (AT, BE and FR); the liberal regime (UK and IE); and the southern regime (ES, IT and EL).

As Figure 1 shows, the sharpest increase in unemployment was between 2008 and 2009 for most countries, but with substantially greater increases in Greece, Spain, Italy and Ireland before the turning point in 2012 and 2013. There is no sign of a fall in unemployment in Italy by 2014, however. Ireland had a very low 

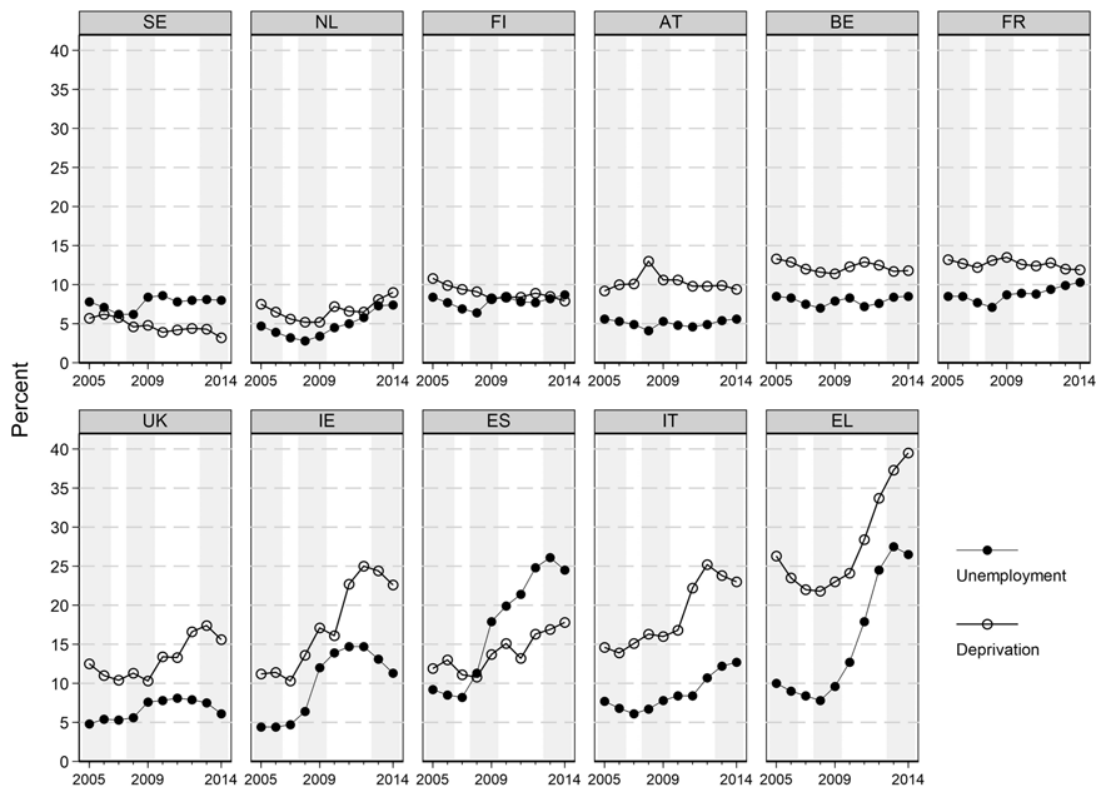

Figure 1. Trends in unemployment rate and material deprivation rate, 2005-2014 Source: Eurostat LFS statistics (unemployment) and EU-SILC (deprivation).

Note: unemployment rate for persons aged 15-74. The vertical grey bands indicate the periods we focus on.

unemployment rate in 2005 at just over $4 \%$. It rose very sharply in the recession, reaching almost $15 \%$ in 2012 before dropping back to just over $11 \%$ by 2014. Spain and Greece began with a higher-than-average unemployment rate (over $8 \%$ for Spain and Greece in 2005). In both countries, it rose very sharply during the recession, reaching over $26 \%$ by 2013 . Italy's unemployment rate was lower than this initially, at about the average across the remaining seven countries; but it rose to a higher level during the recession remaining high at over $12 \%$ in 2014. In the remaining seven countries, the rate averaged about $7 \%$ in 2005 , falling to under $6 \%$ by 2008 before rising in the recession to reach about $8 \%$ in 2014 .

Concerning material deprivation, Figure 1 shows a wide variation between countries and over time. Overall, we see that in the social-democratic and the corporatist regimes, material deprivation never exceeds $15 \%$. Material deprivation is significantly higher in the other regimes, and it reaches the peak of $40 \%$ in Greece in 2014. This country particularly stands out: its lowest value in 2008 (22\%) was higher than the highest reached in all other countries apart from Ireland and Italy mid-recession.

The lowest values were found in the three social-democratic countries, which averaged between 6 and $8 \%$. The impact of the recession is very clear for Greece, Ireland and for Italy. Material deprivation was less responsive to the recession in other countries. 


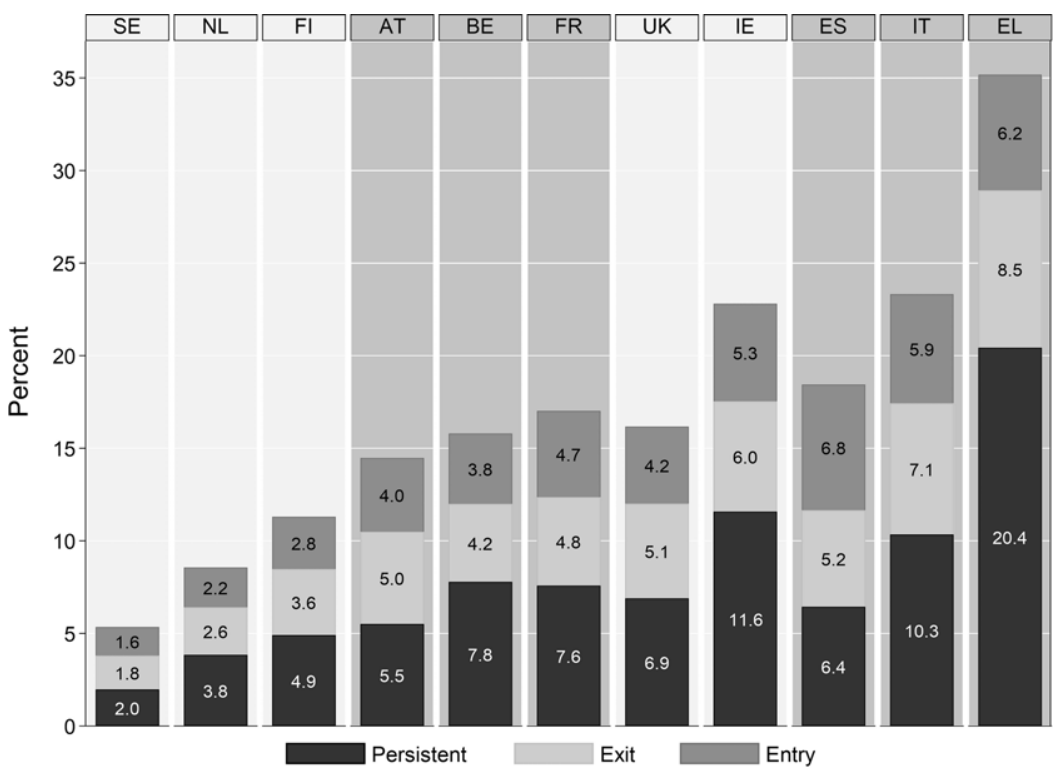

Figure 2. Deprivation dynamics by country, \% (average across periods)

Source: EU-SILC data, for 2005-06, 2008-09 and 2013-14.

\section{The dynamics of material deprivation}

As shown in the previous section, European countries vary significantly in the levels and trends of both unemployment and material deprivation rates. On the one hand, we have found social-democratic countries experience the lowest rates in both outcomes, while on the other hand southern countries and Ireland experience the highest levels of unemployment and deprivation, and the highest increases with the recession.

Figure 2 reports deprivation dynamics for the 11 countries examined. ${ }^{7}$ As noted earlier, we focus on the transitions between 2005 and 2006; 2008 and 2009; and 2013 and 2014. In Figure 2, we pool the three periods and distinguish between those persistently deprived, those entering deprivation and those exiting deprivation.

The overall levels of deprivation - captured by the total height of the bars mirror the unemployment levels presented in Figure 1, in terms of country ranking. Country differences are striking also in this case. Comparing Sweden with Greece, the two countries at the extremes, overall deprivation in the latter is 7 times higher than in the former ( $35 \mathrm{vs} 5 \%$ ), while persistent deprivation is more than 10 times higher (20 vs $2 \%$ ).

Focusing on individuals in households that have experienced some deprivation, Figure 2 shows that individuals are more likely to be persistently deprived rather than to be entering or exiting deprivation. Persistent 
deprivation, indeed, represents the most widespread situation in all countries but Spain. Between $35 \%$ and $58 \%$ of overall dynamics are represented by persistent deprivation. Greece and Ireland represent the worst-case scenarios in terms of deprivation persistence and its contribution to overall deprivation.

The results presented so far are in line with the expectations relating to lower levels of both overall and persistent deprivation for the countries associated with the most generous welfare regimes. However, differences between the $\mathrm{UK}$ and Ireland are greater than might have been expected with the former more closely resembling the corporatist countries.

\section{Persistent deprivation of social risk groups}

In this section, we focus on variation in the most severe deprivation dynamic, i.e. persistent deprivation, across social risk groups. As discussed above, we identify social risk groups based on the challenges individuals face to meet their material needs, including lone parenthood, disability, age-dependency (children, those transitioning to adulthood and people of retirement age). The groups we identify are:

- Lone parents (all ages) and their children;

- Working-age adults aged 18-65 with a disability and their children (excluding lone parents);

- Other children under age 18 (children of two-parent families);

- Other young adults aged 18-29 (not a lone parent and not having a disability);

- Other working-age adults aged 30-65 (not a lone parent and not having a disability);

- Other older adults aged over 65.

Figure 3 shows persistent deprivation rates by country and social risk group. As the figure shows, there is a wide heterogeneity in the risk of being persistently deprived across groups and this is true for all countries. Moreover, the pattern of stratification in deprivation risks is strikingly stable across countries. On the one hand, working age adults (in Figure 3 labelled 'Other 30-65'), other children, and other adults over 65 ('Other 65+') are the groups which experience the lowest risk of being persistently deprived, and experience very similar rates within countries - differences between these groups do not exceed 5 percentage points; on the other hand, people with a disability and especially lone parents are the most disadvantaged groups. This is true for all countries.

Persistent deprivation rates for working age adults aged 30-65, which represents the largest group in size (see Figure A1 in the Appendix) but the least disadvantaged group in most countries, range between $1 \%$ in Sweden and $8 \%$ in Italy, with Greece being an outlier in this case with a rate of $17 \%$. At the other extreme, persistent deprivation for lone parents, who represent the smallest 


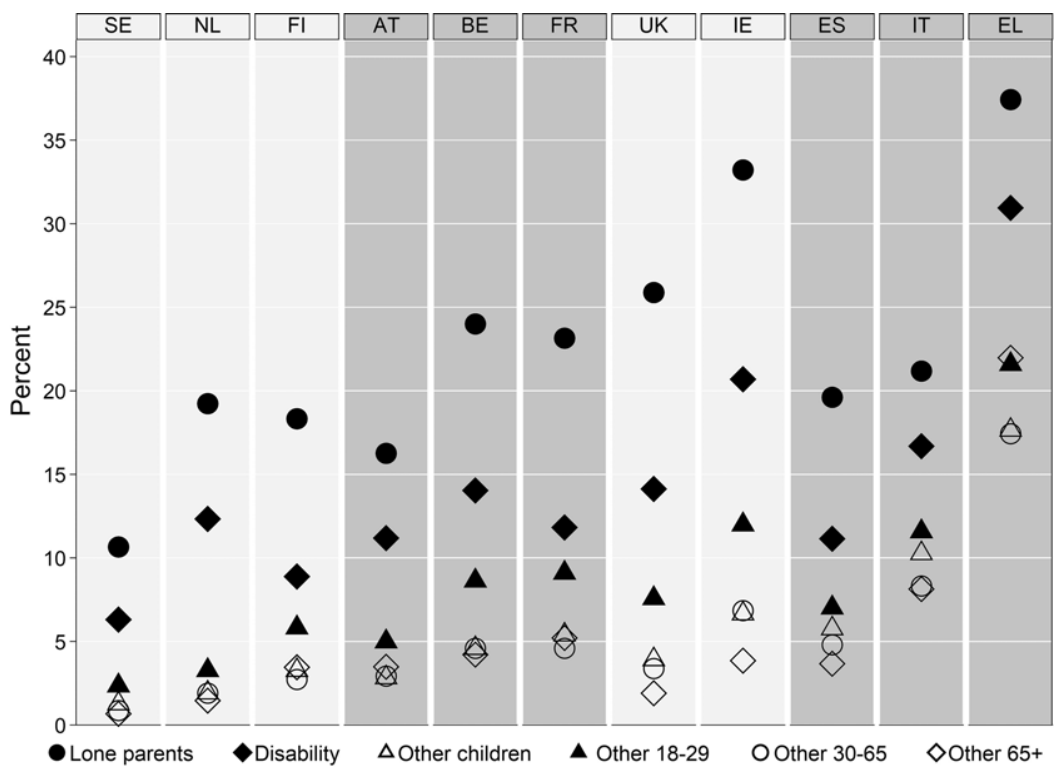

Figure 3. Persistent deprivation of social risk groups by country Source: EU-SILC data, for 2005-06, 2008-09 and 2013-14.

group but the most deprived, ranges between $11 \%$ in Sweden and $37 \%$ in Greece. In all countries, this group is followed by people with a disability and then by young adults ('Other 18-29'). In Greece, older adults have a similarly high deprivation rate to the young adults. In the UK, Ireland and Spain, older adults $65+$ are the least likely to be persistently deprived.

Therefore, to answer our first question we can say that the way in which risks are stratified between groups is remarkably similar across countries. Notwithstanding this, great variation across countries is visible in levels and in the gap in persistent deprivation between the most and the least disadvantaged groups.

\section{Social risk gap}

Here, we focus on the two groups that are distinctive in their experience of persistent deprivation, namely lone parents and people with a disability. In Figure 4 we present what we term the 'social risk gap' which represents the absolute gap in persistent deprivation for the two most disadvantaged groups and the reference group represented by working-age adults - the largest and generally least disadvantaged group.

The gap for lone parents is represented in Figure 4 by a dot while the gap for people with a disability is represented by a triangle. The patterns that we observe across countries do not conform closely to our expectations: a smaller gap in countries characterized by a generous welfare state. Looking at lone parents, 


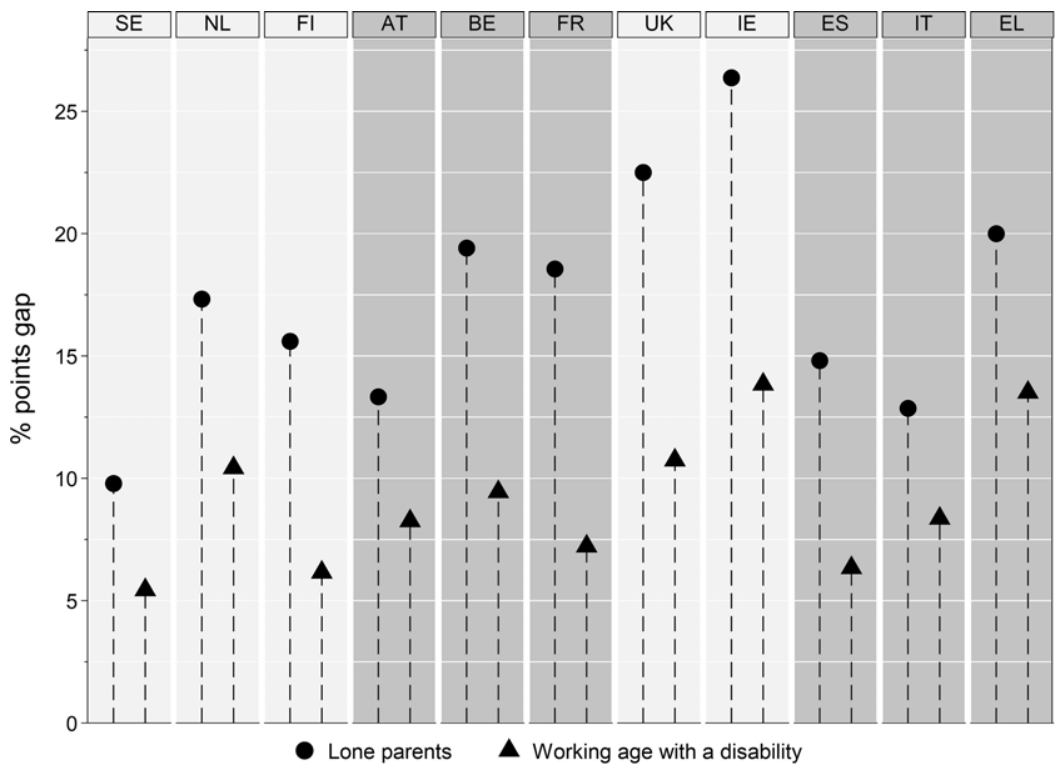

Figure 4. Social risk gap. Persistent deprivation gap for lone parents and people with a disability compared with working age adults, by country

Source: EU-SILC data, for 2005-06, 2008-09 and 2013-14.

while, on the one hand, they present the largest risk gap in Ireland (almost 27 percentage points) and the United Kingdom (22.5 percentage points), on the other hand we do not observe the smallest gap in the social-democratic countries. ${ }^{8}$ While Sweden is certainly the country that provides the best protection for this group with a gap of 10 percentage points, Italy and Spain perform better than Finland and the Netherlands. Corporatist countries lie between the liberal and the southern countries.

Concerning people with a disability, we observe a considerably smaller gap compared with lone parents, and certainly much more similar gaps across countries. Indeed, while the gap for lone parents has a range of 17 percentage points (comparing the two extremes Sweden and Ireland), the gap for people with a disability has a range of 8 percentage points (comparing the extremes Sweden and Ireland again). No clear pattern is observed across welfare regimes. Although Greece certainly emerged as the country where persistent deprivation was more widespread (with an overall rate of $20.4 \%$ ), it does not represent the most unequal country in the way deprivation risks are distributed across groups.

Overall, our hypothesis that the social risk gap was larger in less generous welfare systems is not fully supported. Indeed, vulnerable groups do not seem to be more protected in more generous welfare regimes. 


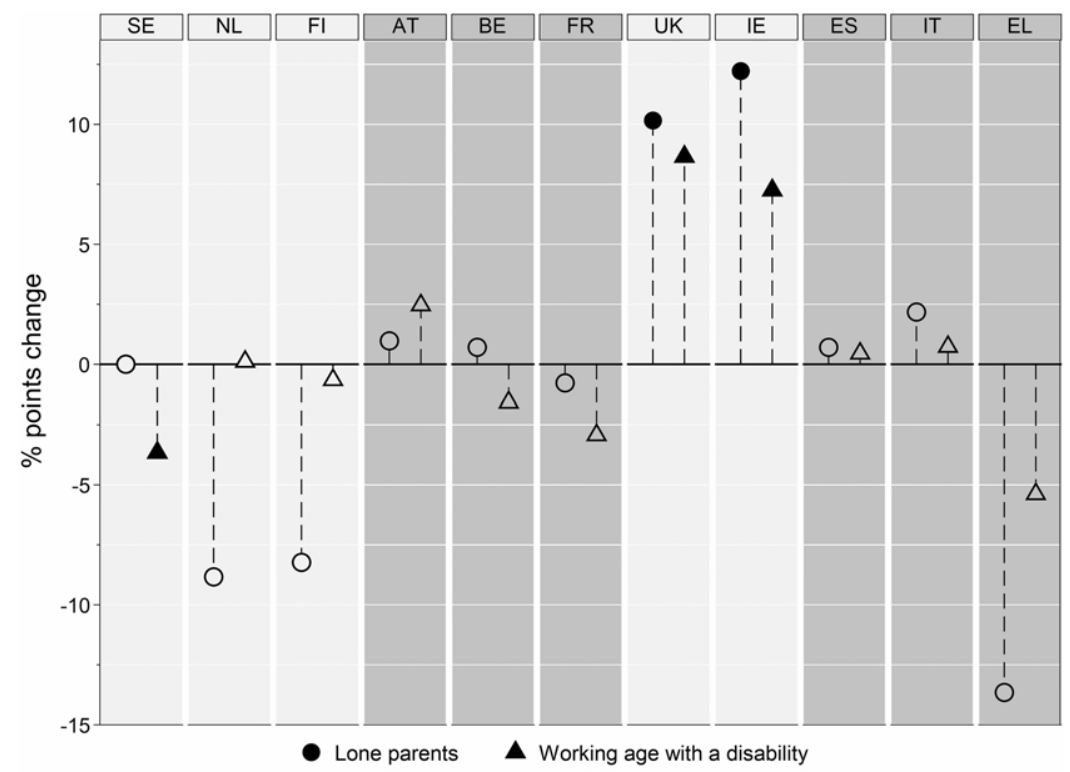

Figure 5. Changes between 2005-06 and 2013-14 in the social risk gap. (Solid symbols indicate statistically significant changes at $95 \%$ )

Source: EU-SILC data, for 2005-06 and 2013-14.

\section{Social risks and the recession}

As a final step, we investigate the extent to which the recession led to polarisation or convergence between the vulnerable social risk groups and the more advantaged groups. Figure 5 reports changes between 2005-06 and 2013-14 in the social risk gap. A positive change indicates that the gap between the vulnerable and advantaged groups has increased over time, signalling polarisation. A negative change indicates convergence. Solid symbols indicate that the changes in the social risk gap are statistically significant at the conventional $95 \%$ level.

For most of the countries, the absolute gap for lone parents and people with a disability compared to the reference group has not registered a statistically significant change over time, as indicated by the empty symbols in the Figure 5. In many cases (e.g. Greece) a seemingly large change did not reach statistical significance possibly because of the small size of the group in question (see Appendix Figure A1).

The only significant changes were for the two liberal countries and Sweden. The United Kingdom and Ireland experienced an increase of more than 10 percentage points in the social risk gap for lone parents and an increase of between 7 and 9 percentage points for working age people with a disability. This indicates a polarisation of the social risk gap in persistent deprivation for both lone parents and people with a disability in the two liberal countries. The only sign 
of statistically significant convergence is registered in Sweden for working age people with a disability, who experience a decrease in the social risk gap of about 4 percentage points.

\section{Conclusions}

Atkinson and Morelli (2011: 49) in an analysis of the relationship between economic crisis and inequality conclude that there is no hard and fast pattern and crises differ greatly from each other in their causes and outcomes. Focusing specifically on the recent Great Recession, Jenkins et al. (2013) showed that the initial distributional effects varied widely across countries, reflecting differences not only in the macroeconomic downturn but also in the cushioning effects of cash transfers and direct taxes. Thus, it is far from clear whether the literature relating to long-term trends in inequality enables us to understand the impact of the recent economic crisis and the way it has varied across countries.

Whelan and colleagues (2017), focusing on trends in income, material deprivation and economic stress provided evidence of the extent to which the impact of the Great Recession varied even among the hardest hit countries, and even more so between them and the less affected countries. Several studies have shown the advantage of going beyond income and incorporating direct measures of material deprivation to understand the socio-economic distribution of the impact of economic shocks. In this paper, we have sought to extend this approach by focusing on a comparative analysis of the deprivation dynamics for social risk groups. In adopting this approach, we sought to address some of the problems involved in operationalising Sen's distinction between functionings and capabilities by providing a stronger basis for inferences relating to the latter based on the observation of the former. Countries included in the study cover different welfare regimes and the time span covered goes from the pre- to the post-recession period.

It is worth noting that the countries included in the analysis had very different experiences with the recession over the period. Focusing on the unemployment rate as a key indicator of the capacity of individuals and families to meet their needs through the market, three countries stand out: Spain, Greece and Ireland. Countries' different experiences are reflected in the changes over time in material deprivation, with very sharp increases in Greece; sharp increases in Ireland; and a substantial, though less dramatic, increase in Spain, perhaps moderated by familial supports in this country. Italy also experienced a sizeable increase in material deprivation, similarly to Ireland from 2010 onwards. Most of the increase in deprivation happened during the course of the recession rather than at the very start in 2008-09. This is consistent with households maintaining their standard of living by drawing on accumulated resources in the early recession but curtailing consumption later as resources are eroded. 
Our results show that two groups stood out as having substantially higher levels of (persistent) material deprivation: lone parent families and families affected by working age disability. Both groups had a markedly higher deprivation rate than the reference group of other adults aged 30-65. In line with our expectations, the ranking of social risk groups in terms of deprivation rates was roughly the same in all countries, although with varying levels of deprivation. Contrary to our expectations, instead, the deprivation gap between both lone parents and working-age adults with a disability and the less vulnerable groups was uniform across countries. In fact, the social risk gap was not appreciably smaller in the most generous countries of the social-democratic regime, but the gap tended to be noticeably larger in the two liberal countries characterized by less generous welfare provision, the UK and Ireland. It is striking that the same two groups emerged as experiencing higher deprivation rates across very different types of welfare system. This suggests that none of the systems is particularly successful at addressing the particular barriers faced by these groups, and that the liberal system is distinctively worse in this respect.

Finally, we investigated the impact of the recession across social risk groups. Our results suggest that there was no overall evidence of polarisation in material deprivation in the sense of an increase in the gap between the two vulnerable groups and the reference group. There were differences in this respect between countries, however. Again, the most distinctive pattern was found for the two liberal countries, the UK and Ireland. These countries, with their means-tested, targeted approach that emphasises cash transfers performed poorly in protecting the living standards of vulnerable groups during the recession as reflected in a polarisation in persistent deprivation.

The limited evidence for 'hard and fast patterns' relating to the nature of the relationship between economic crisis and persistent inequality means that a fuller explanation of trends in polarisation clearly requires a more detailed focus on micro-factors or country-specific welfare provision. However, data limitations relating to the quality of the panel data in the EU-SILC are likely to set severe constraints on the extent to which such a comparative agenda can be successfully pursued employing that source.

Our use of the welfare regime approach was intended to bring out similarities and differences in the short-term effects of the Great Recession. Clearly such approaches ultimately need to be complemented by in depth historical analysis of specific contexts and strategic responses of individual countries as in Eichengreen's (2015) treatment of Iceland, Ireland and Greece. Furthermore, while the data available to us mean that our focus was necessarily on short-term effects, inevitably the impact of the Great Recession will involve much longerterm effects. This is likely to be particularly true in relation to its consequences for children and hopefully the increasing availability of longitudinal cohort studies will allow these issues to be addressed. Ultimately addressing the issues of 
winners and losers will require longitudinal and comparative analysis at both macro and micro levels.

To conclude, we should note that the emphasis, on whether there was a polarisation or convergence of social risk, might lead to missing some important nuances. Polarisation can hide a good news story if the circumstances of all families improve but the polarisation is due to a faster improvement for the initially advantaged group. Convergence can hide a worrying story if it is driven by a deterioration in the circumstances of the initially advantaged group with no real improvement for the vulnerable group.

\section{Supplementary material}

To view supplementary material for this article, please visit https://doi.org/10. $1017 /$ So047279421000210

\section{Notes}

1 For a recent discussion of popular attitudes to welfare mixes see Taylor-Gooby et al. (2020).

2 For a detailed discussion of the continuing value and limitations of the Esping-Andersen schema see Arts and Gelissen (2010).

3 Severe material deprivation is an EU indicator that measures the proportion of the population lacking at least four of the nine items listed in the EU index of material deprivation (see definition below). Low work intensity measures the labour market attachment of all household members; individuals are defined as living in a low work intensity household if working-age household members worked for less than $20 \%$ of their potential during the previous year (Ayllón and Gábos, 2017).

4 Data we use is UDB ver 2014-3 from 01-03-17.

5 The Europe 2020 strategy aims to promote smart, sustainable and inclusive growth in Europe for the period 2010 to 2020 across five areas, employment, research and development, climate change and energy, education and poverty and social exclusion.

6 In some countries, such as France (where individuals are followed 8 years) and those that have population registers, the sample design deviates. Representativeness of the population is anyway guaranteed (Eurostat, 2018, p. 23). More details about sampling design in the register countries can be found in Jäntti et al. (2013).

7 The background of the bars in Figure 2 (as well as in all the figures that will follow) are of a different shade of grey in order to separate countries belonging to different regimes.

8 Here, we have to bear in mind that the reference group in social-democratic countries experiences somehow lower levels of deprivation than in other countries, especially the southern countries and Ireland. Had we computed the social risk gap in relative rather than absolute terms, results would have been rather different. We avoid this because the relative gaps are overly influenced by the rate for the most advantaged group.

\section{References}

Albertini, M., Kohli, M. and Vogel, C. (2007), 'Intergenerational Transfers of Time and Money in European Families: Common Patterns - Different Regimes?', Journal of European Social Policy, 17, 319-334. 
Alkire, S., Foster, J., Seth, S., Santos, M. E., Roche, J. M. and Ballón, P. (2015), Multidimensional Poverty Measurement and Analysis, Oxford University Press.

Arts, W.A. and Gelissen, J. (2010), 'Models of the welfare state', in S. Leibfried, J. Lewis, H. Obinger and C. Pierson, (eds.), The Oxford handbook of the welfare state, Oxford: Oxford University Press, 569-83.

Atkinson, A. and Morelli, S. (2011), 'Economic Crisis and Inequality', UNDP-HDRO Occasional Papers, 2011/06.

Attias-Donfut, C., Ogg, J. and Wolff, F. C. (2005), 'European patterns of intergenerational financial and time transfers', European Journal of Ageing, 2, 3, 161-173.

Ayllón, S. (2008), 'Modelling poverty transitions in Spain: Do attrition and initial conditions really matter?', IRISS Working Papers, 2008-08.

Ayllón, S. and Gábos, A. (2017), 'The Interrelationships between the Europe 2020 Poverty and Social Exclusion Indicators, Social Indicators Research, 130, 1025-1049.

Bane, M.J. and Ellwood, D. (1986), 'Slipping into and out of poverty: the dynamics of spells', Journal of Human resources, 21, 1-23.

Beck, U. (1992), Risk Society. Towards a New Modernity. London: Sage.

Brandt, M. and Hank, K. (2013), 'Scars that will not disappear: long-term associations between earlier and later life unemployment under different welfare regimes', Journal of Social Policy, 43, 4, 727-743.

Cappellari, L. and Jenkins, S.P. (2004), 'Modelling low income transitions', Journal of Applied Econometrics, 19, 5, 593-610.

Daly, M. (2002), 'Care as a good for Social Policy', Journal of Social Policy, 31, 2, 251-270.

Dewilde, C. (2003), 'A life course perspective on social exclusion and income poverty, British Journal of Sociology, 54, 1, 109-128.

Duncan, G.J. and Brooks-Gunn, J. (1999), Consequences of growing up poor. New York: Russell Sage Foundation.

Eichengreen, B. (2015), Hall of Mirrors: The Great Depression, the Great Recession and the Uses and Misuses of History, Oxford University Press

Esping-Andersen, G. (1990), The Three Worlds of Welfare Capitalism, Oxford: Polity Press.

Eurofound (2007), Occupational mobility in Europe, Publications Office of the European Union, Luxembourg.

European Commission (2015), Portfolio of EU Social Indicators for the Monitoring of Progress Towards the EU Objectives for Social Protection and Social Inclusion - 2015 update, Brussels: Directorate for Employment, Social Affairs and Equal Opportunities, European Commission, http://ec.europa.eu/social/BlobServlet?docId=14239\&langId=en.

Eurostat (2018), Methodological Guidelines and Description of EU-SILC Target Variables, 2017 operation (Version September 2017), European commission, https://ec.europa. eu/eurostat/documents/203647/203704/Guidelines+SILC+2018/.

Ferrera, M. (1996), 'The «Southern Model» of Welfare in Social Europe', Journal of European Social Policy, 6, 1, 17-37.

Fouarge, D. and Layte, R. (2005), 'Welfare regimes and poverty dynamics: The duration and recurrence of poverty spells in Europe', Journal of Social Policy 34, 407-26.

Freeman, R. and Rothgang, H. (2010), 'Health', in F.G. Castles, S. Liebfried, J. Lewis, H. Obinger and C. Pierson, (eds.), The Oxford Handbook of the Welfare State, Oxford University Press, 367-377.

Gallie, D. and Paugam, S. (2000), 'The Experience of Unemployment in Europe', in D. Gallie and S. Paugam (eds.), Welfare Regimes and the Experience of Unemployment in Europe, Oxford: Oxford University Press.

Gibson-Davis, C. M. (2016), 'Single and Cohabiting Parents and Poverty' in D. Brady, and L. M. Burton (eds.), The Oxford Handbook of The Social Science of Poverty, Oxford University Press, 417-437.

Goldthorpe, J. H. (2007), On Sociology, Vol. 1, 2nd ed., Stanford: Stanford University Press.

Goldthorpe, J. H. (2007b), On Sociology, Vol. 2, 2nd ed., Stanford: Stanford University Press. 
Goldthorpe, J. H. and Jackson, M. (2008), 'Education Based Meritocracy: The Barrier to its Realization', in A. Lareau and D. Conley (eds.), Social Class How Does it Work, New York: Russell Sage Foundation, 93-117.

Grotti, R., Maître, B., Watson, D. and Whelan, C. (2017), 'Poverty Transitions in Ireland: An Analysis of the longitudinal Central Statistics Office (CSO) Survey on Income and Living Conditions (SILC), 2004-2015'. Social Inclusion Technical Paper No. 8, Dublin: Department of Employment Affairs and Social Protection.

Guio, A. C. and Marlier, E. (2017), 'Amending the EU Deprivation Indicator: Impact on Size and Composition of Deprived Population', in A.B. Atkinson, A.C. Guio and E. Marlier (eds.), Monitoring social inclusion in Europe, Luxembourg: Publications Office of the European Union, 193-208.

Guio, A. C., Marlier, E. and Pomati, M. (2017), 'Evolution of material deprivation over time: the impact of the great recession in EU countries', in A.B. Atkinson, A.C. Guio and E. Marlier (eds.), Monitoring social inclusion in Europe, Luxembourg: Publications Office of the European Union, 367-384

Hick, R. and Burchardt, T. (2016), 'Capability Deprivation', in Brady, D. and Burton, L. (eds), The Oxford Handbook of the Social Science of Poverty, Oxford, Oxford University Press, 76-92.

Jäntti, M., Törmälehto, V.-M. and Marlier, E. (2013), 'The use of registers in the context of EU-SILC: challenges and opportunities', Eurostat Methodologies and working papers, Publications office of the European Union, Luxembourg.

Jenkins, S. (1999), 'Modelling household income dynamics', Journal of Population Economics, $13,529-67$.

Jenkins, S. P., Brandolini, A., Micklewright, J. and Nolan, B. (2013), The Great Recession and the distribution of household income. Oxford: Oxford University Press.

Jenkins, S.P. and Van Kerm, P. (2017), 'How does attrition affect estimates of persistent poverty rates? The case of EU SILC', in A.B. Atkinson, A.C. Guio and E. Marlier (eds.), Monitoring social inclusion in Europe, Luxembourg: Publications Office of the European Union, 401-418.

Kenworthy, L. (2010), 'Labour Market Activation', in F.G. Castles, S. Liebfried, J. Lewis, H. Obinger and C. Pierson, (eds.), The Oxford Handbook of the Welfare State, Oxford University Press, 435-447.

Kohli, M. and Albertini, M. (2008), 'The family as a source of support for adult children's own family projects: European varieties', in C. Saraceno (eds.), Families, Ageing and Social Policy: Intergenerational Solidarity in European Welfare States, Cheltenham: Edward Elgar, 38-58.

Krell, K., Frick, J. R. and Grabka, M. M. (2017), 'Measuring the Consistency of Cross-Sectional and Longitudinal Income Information in EU-SILC', Review of Income and Wealth, 63, 1, $30-52$.

Kus, B., Nolan, B. and Whelan, C. T. (2016), 'Material Deprivation and Consumption', in Brady, D. and Burton, L. (eds.), The Oxford Handbook of The Social Science of Poverty, New York: Oxford University Press, pp. 577-60.

Leisering, L. and Liebfried, S. (1999), Time and Income poverty in Western Welfare States: United Germany in Perspective, Cambridge: Cambridge University Press.

Macmillan, R. and Copher, R. (2005), 'Families in the Life Course: Interdependency of Roles, Role Configurations, and Pathways', Journal of Marriage and Family, 67, 4, 858-879.

Nolan, B. and Whelan, C. T. (2011), Poverty and Deprivation in Europe, Oxford: Oxford University Press.

Pintelon, O., Cantillon, B., Van Den Bosch, K. and Whelan, C. T. (2013), 'The social stratification of social risks: The relevance of class for social investment', Journal of European Social Policy, 23, 1, 52-67.

Polin, V. and Raitano, M. (2014), 'Poverty Transitions and Trigger Events across EU Groups of Countries: Evidence from EU-SILC', Journal of Social Policy, 43, 4, 745-772. 
Power, C., Manor, O. and Matthews, S. (1999), 'The duration and timing of exposure: effects of socio-economic environment on adult health', American Journal of Public Health, 89, 1059-1065.

Priestley, M. (2010), 'Disability', in F.G. Castles, S. Liebfried, J. Lewis, H. Obinger and C. Pierson, (eds.), The Oxford Handbook of the Welfare State, Oxford University Press, 406-419.

Ringen, S. (1988), 'Direct and Indirect Measures of Poverty', Journal of Social Policy, 17, 351-366.

Sen, A. K. (1992), Inequality Reexamined, Oxford: Oxford University Press.

Sen, A. K. (2009), The Idea of Justice, London: Allen Lane.

Taylor-Gooby, P. (2004), 'New Risks and Social Change', in P. Taylor-Gooby (eds.), New Risks, New Welfare: The Transformation of the European Welfare State, Oxford: Oxford University Press, 1-28.

Taylor-Gooby, P., Heuer, J-O., Chung, H., Leruth, B., Mau, S. and Zimmermann, K. (2020), 'Regimes, Social Risk and Welfare Mix: Unpacking Attitudes to Pensions and Childcare in Germany and the UK through deliberative forums', Journal of Social Policy, 49, 1, 61-79.

Vandecasteele, L. (2010), 'Poverty Trajectories after Risky Life Course Events in Different European Welfare Regimes', European Societies, 12, 2, 257-278.

Walker, R. (1994), Poverty Dynamics: Issues and Examples, Aldershot: Avebury.

Watson, D., Maître, B. and Kingston, G.(2014), Developing a country typology for analysing quality of life in Europe, (A Report of the European Foundation for the Improvement of Living and Working Conditions), Luxembourg: Publications Office of the European Union.

Western, B., Bloom, D., Sosnaued, B. and Tach, L. (2012), 'Economic Insecurity and Social Stratification', Annual Review of Sociology, 38, 341-359

Whelan, C.T., Nolan, B. and Maitre, B. (2017), Polarization or "Squeezed Middle" in the Great Recession?: A Comparative European Analysis of the Distribution of Economic Stress. Social Indicator Research 133, 163-184. 